\title{
Analisa Metode Webqual 4.0 dan Importance- Performance Analysis (IPA) Pada Kualitas Situs Detik.com
}

\author{
Diana Apriliani, Muhammad Fikry, Marnala J. Hutajulu \\ Program Studi Administrasi Bisnis, Fakultas IImu Sosial Dan IImu Politik, \\ Universitas Mulawarman, Jl. Muara Muntai, Gn. Kelua, Kec. Samarinda Ulu, Kota Samarinda, \\ Kalimantan Timur, Indonesia-75411 \\ E-mail: nadinapriliani25@gmail.com fikryaransyah@fisip.unmul.ac.id \\ Marnalahutajulu@fisip.unmul.ac.id
}

\begin{abstract}
Abstrak
Maksud dari penelitian ini ialah untuk menelaah apakah situs web Detik.com telah sinkron dengan kaidah pelayanan situs web yang baik dan benar, serta melakukan evaluasi untuk mengukur dan meningkatkan serta memperbaiki kualitas layanannya yang masih kurang. Metode yang digunakan adalah metode webqual 4.0 dan Importance-Performance Analysis (IPA). Hasil dari perhitungan rata-rata nilai kesenjangan (GAP) pada website Detik.com memberikan angka negatif $(<0)$ yaitu sebesar $-0,04$, angka terbilang dapat menggambarkan bahwa taraf kinerja website Detik.com masih minim dan belum menyanggupi harapan penggunanya. Kuadran IPA memberikan hasil 1 indikator yang terdapat dalam kuadran 1, 10 indikator pada kuadran II, 7 indikator pada kuadran III, dan 4 indikator masuk ke dalam kuadran IV. Hasil dari penelitian ini diharapkan bisa memberikan masukan terhadap pihak Detik.com khususnya pihak yang mengelola website Detik.com, serta bisa dijadikan sebagai bahan evaluasi untuk meningkatkan dan mempertahankan kualitas layanannya serta dapat memenuhi harapan pengguna layanan atau pengunjung website Detik.com.
\end{abstract}

Kata Kunci: Importance-Performance Analysis (IPA), Kualitas Layanan, Website Detik.com, Webqual 4.0

Abstract

The purpose of this research is to examine whether the website Detik.com has been synchronized with the rules of good and correct website services, and conduct evaluations to measure and improve and improve the quality of services that are still lacking. The method used is the Webqual 4.0 method and Importance-Performance Analysis (IPA). The results of the calculation of the average gap value (GAP) on the website Detik.com gives a negative number $(<0)$ in the amount of -0.04 , a number that can illustrate that the level of performance of the website Detik.com is still minimal and does not meet the expectations of users. The IPA quadrant provides the results of 1 indicator contained in quadrant 1, 10 indicators in quadrant II, 7 indicators in quadrant III, and 4 indicators entered into quadrant IV. The results of this study are expected to provide input to Detik.com, especially those who manage the Detik.com website, and can be used as evaluation material to improve and maintain the quality of its services and can meet the expectations of service users or visitors to the Detik.com website.

Keywords: Importance-Performance Analysis (IPA), Service Quality, Website Detik.com, Webqual 4.0 


\section{Pendahuluan}

Kemajuan dari teknologi informasi sejak abad ke-21 mampu menghadirkan hal-hal baru yang bisa semakin mempermudah kebutuhan hidup sehari-hari, salah satu contohnya adalah hadirnya internet. Teknologi dapat dimanfaatkan dan berperan penting untuk memenuhi tujuan bisnis ataupun digunakan untuk membagikan informasi yang penting [1]. Teknologi informasi sebagai acuan dalam perkembangan jaman mengakibatkan kebutuhan informasi meningkat tajam, Internet merupakan salah satu faktor pendukung dari teknologi dalam pengembangan bisnis dan membagikan informasi untuk masyarakat yang turut serta menggunakan internet [2]. Di dunia bisnis, internet memberikan dampak positif yang memberikan perubahan dalam menciftakan pandangan baru untuk berbisnis, yaitu digitial marketing atau internet marketing (cyber marketing, electronic marketing) dan sejumlah istilah lainnya. Berbisnis dengan memanfaatkan teknologi mempunyai prospek yang cukup besar dan hampir semua orang menginginkan kepraktisan dan kemudahan dalam hal tersebut [3]. Di dunia komunikasi sendiri sekarang sudah dikenal dengan istilah new media, media teknologi komunikasi yang melibatkan komputer ataupun gadget melalui jaringan internet atau biasa disebut media online. Media online adalah salah satu praktik jurnalistik yang modern saat ini. Menurut Syarifuddin Yunus [4] website, blog dan lainnya yang terbit/tayang di dunia maya, dapat dibaca dan dilihat di internet merupakan pengertian dari media online. Melalui kumpulan dari page di www (world wide wibe) berbasis internet, manusia bisa mendapatkan semua informasi yang dibutuhkan, dan sarana komunikasi yang cepat serta murah hanya dengan melalui web (website).

Di Indonesia sendiri terjadi peningkatan perusahaan media yang memanfaatkan internet dengan menyediakan situs web berita. Beberapa diantaranya seperti Detik.com yang menjadi objek dari penelitian ini, Kompas, Tribunnews, dan situs berita lainnya. Pertumbuhan new media ini juga mampu membuat keberadaan media cetak semakin berkurang. Hasil survey yang dilakukan oleh Nielsen Indonesia (2014) menyatakan bahwa penetrasi media cetak yaitu koran mengalami penurunan dari 15\% pada tahun 2010 menurun hingga 11\% di tahun 2014 . Sebaliknya, penertrasi media online mengalami kenaikan dari $17 \%$ menjadi $34 \%$. Menurut data Alexa (2019), dari banyaknya situs berita yang paling banyak dikunjungi atau dibaca adalah Tribunnews sedangkan Detik.com berada di urutan kedua. Berdasarkan dari hasil penelitian yang dilakukan oleh Anisatul Kamaliyah (2017) yang merupakan mahasiswi dari Universitas Islam Negeri Jakarta dengan judul "Kepuasan Mahasiswa UIN Jakarta Terhadap Situs Media Online: Komparasi Tribunnews.com Dengan Detik.com" [5], memberikan kesimpulan bahwa portal website Tribunnews.com lebih memuaskan jika dibandingkan dengan portal website Detik.com dengan beda tingkat kesenjangan kepuasan sebesar 0,0684. Berdasarkan atas permasalahan yang telah peneliti uraikan diatas, penelitian ini bertujuan untuk menganalisis apakah situs web Detik.com telah sinkron dengan kaidah pelayanan situs web yang baik dan benar, melakukan evaluasi untuk mengukur dan meningkatkan serta memperbaiki kualitas layanannya yang masih kurang.

Peneliti menggunakan mahaiswa sebagai populasi dalam peneltian ini karena mahasiswa merupakan jembatan antara rakyat Indonesia dengan pemerintah untuk menyampaikan aspirasi karena menjadi mahasiswa memiliki salah satu peran atau fungsi sebagai agent of change atau agen perubahan bangsa. Mahasiswa sebagai golongan cendikiawan sudah sepatutnya untuk menanamkan sikap pemberini dan kritis serta tanggap terhadap kebijakan para pemegang roda pemerintahan. Agent of change yang melekat pada mahasiswa mengartikan bahwa mahasiswa harus selalu mengetahui apa saja yang terjadi di negaranya dan kebijakan apa saja yang akan dilaksanakan oleh pemerintah. Mahasiswa harus mendapatkan atau menerima informasi dari situs berita yang terpercaya agar tidak salah dalam menyikapi dan mengkritisi kejadian atau kebijakan dari pemerintah.

Metode Webqual 4.0 adalah salah satu metode yang peneliti gunakan pada penelitian ini dikarenakan metode ini lebih sesuai dengan pokok permasalahan yang akan ditelaah oleh peneliti. Webqual yaitu salah satu metode yang bisa dipakai untuk mengukur dan menganalisa kualitas sebuah website yang dilihat dari persepsi atau pandangan dari pengguna akhirnya [6]. Hasil dari metode ini berfokus terhadap tiga dimensi kualitas website yaitu: usability quality atau kualitas penggunaan, information quality atau kualitas informasi, dan service interaction quality atau kualitas layanan.

Kemudian metode IPA diikutsertakan dalam analisis ini karena metode ini mendukung dalam pengolahan data. Importance-Performance Analysis (IPA) merupakan gabungan dari pengukuran faktor tingkat importance dan performance dalam grafik dua dimensi yang 
memudahkan dalam menyampaikan data dan usulan praktis untuk objek yang teliti. Kemudian dianalisa menggunakan Importance-Performance Analysis dalam Matrix, yang mana sumbu X mewakili importance dan sumbu Y mewakili Performance [7].

Hasil dari penelitian ini berupa analisis terhadap setiap variabel webqual 4.0 dan menunjukkan analisa kesenjangan antara harapan pengguna website Detik.com dengan kinerja yang ditawarkan atau diberikan oleh website Detik.com. Hal ini membuat peneliti untuk melakukan penelitian yang berjudul "Analisa Metode Webqual 4.0 Dan Importance-Performance Analysis (IPA) Pada Kualitas Situs Detik.com".

\section{Metodologi Penelitian}

Pada penelitian ini peneliti memilih deskriptif kuantitatif. Penelitian deskriptif yaitu penelitian yang dipakai yang berguna untuk memberikan suatu deskripsi terhadap suatu fenomena sosial/alam secara sistematis, faktual dan aktual. Peneliti ingin membuat penelitan ilmiah yang sistematis dengan memberikan fakta dan hasil penelitian dengan bentuk data berupa angka-angka hasil perhitungan. Menurut Sugiyono (2015) penelitian ini dikategorikan sebagai metode kuantitatif karena data penelitian berupa angka-angka dan analisis dengan menggunakan metode statistik [8].

\subsection{Teknik Pengumpulan Data}

Menganalisis keadaan yang terajadi atau keadaan yang ingin dikaji dan mengumpulkan data-data yang berhubungan dengan penelitian yang dilakukan merupakan tujuan dari teknik pengumpulan data. Wawancara, kuesioner, observasi secara langsung, dan kepustakaan, merupakan teknik pengumpulan data yang peneliti gunakan dalam penelitan ini.

\subsection{Populasi, Sampel \& Sampling}

Wilayah generasi yang terdiri dari obyek/subyek yang memiliki kualitas dan karakteristik tertentu yang ditetapkan oleh peneliti yang digunakan untuk dipelajari lalu dibuat kesimpulan, merupakan pengertian dari populasi [9]. Populasi yang diambil pada penelitian ini yaitu anggota Himpunan Mahasiswa Administrasi Bisnis Universitas Mulawarman berjumlah 70 orang yang terdiri dari mahasiswa angkatan 2017-2019.

Sampel adalah bagian dari jumlah dan karakteristik yang dipunyai oleh populasi tersebut. Arikunto [10], jika populasi yang digunakan pada penelitian ini kurang dari 100 orang maka sebaiknya populasinya digunakan semuanya semuanya, dan jika populasi yang digunakan lebih dari 100 orang maka peneliti dapat mengambil $20 \%-25 \%$ atau lebih. Populasi yang dipakai pada penelitian ini tidak sampai 100 orang, maka peneliti menggunakan semua jumlah populasi yang ada sejumlah 70 orang.

Teknik sampling dalam penelitian ini mengambil Non Probability Sampling yaitu jenis sampling jenuh. Teknik penentuan sampel yang menggunakan seluruh anggota dari populasi untuk dipakai sebagai sampel merupakan pengertian dari sampling jenuh [8].

\subsection{Teknik Analisis Data}

Teknik analisis data menggunakan uji validitas (test of validity) dan uji keandalan (test of realiability) yang dilakukan untuk menguji kesungguhan dan kebenaran jawaban responden. Kuesioner yang peneliti sebarkan hasilnya diuji dengan uji validitas dan reliabilitas dengan menggunakan aplikasi SPSS (Stastitical of Social Sciencies) versi 23.

\section{$2.4 \quad$ Pengolahan Data}

Ada dua metode yang dugunakan dalam pengolahan data untuk mengevaluasi kualitas pelayanan yang dilhat dari selisih antara harapan pengguna dengan kinerja yang telah diberikan. Metode pertama yaitu metode Webqual 4.0. Metode ini yang dipakai dengan berfokus terhadap tiga dimensi webqua kualitas website yaitu: usability quality (kualitas penggunaan), information quality (kualitas informasi), dan service interaction quality (kualitas layanan interaksi).

Metode Importance-Performance Analysis (IPA) merupakan metode kedua yang dipakai dalam penelitian ini. Pada metode ini menampilkan diagram scater dari ImportancePerformance Analysis dengan memiliki kriteria-kriteria yang terdapat pada 4 kuadran. IPA bertujuan untuk mengukur keterkaitan antara persepsi dengan harapan konsumen dan prioritas peningkatan kualitas produk atau jasa yang biasanya dikenal dengan quadran analysis [11]. 


\section{Kajian Pustaka}

\subsection{Webqual 4.0}

Webqual ialah salah satu metode atau teknik pengukuran kualitas website berdasarkan persepsi pengguna akhir. Metode ini juga merupakan pengembangan dari SERVQUAL yang telah banyal digunakan untuk pengukuran kualitas jasa. Metode ini telah digunakan sejak tahun 1998 yang di mulai dari webqual 1.0 sampai saat ini webqual 4.0 [12]. Hasil dari webqual 4.0 [6] berfokus terhadap tiga dimensi kualitas website yaitu Usability Quality (kualitas penggunaan), Information Quality (kualitas informasi), dan Service Interaction Quality (kualitas layanan interaksi).

\section{Usability Quality}

Sebuah mutu yang berkaitan dengan rancangan sebuah website, contohnya adalah penampilan website, kemudahan bernavigasi dan gambaran yang disampaikan oleh pengguna.

2. Information Quality

Sebuah mutu yang dilihat dari isi yang terdapat pada website tersebut, layaknya tidaknya informasi untuk disampaikan seperti informasi yang akurat, format dan keterkaitanya.

3. Service Interaction Quality

Sebuah mutu yang berhubungan dengan layanan interaksi yang dialami atau dirasakan oleh pengguna ketika menelusuri website.

Indikator-indikator yang terdapat dalam setiap varibel dapat dilihat pada Tabel 1.

Tabel 1. Indikator Webqual 4.0

\begin{tabular}{|c|c|c|}
\hline No & Variabel & Indikator webqual 4.0 \\
\hline \multirow{8}{*}{1} & \multirow{8}{*}{ Kualitas Penggunaan } & $\begin{array}{l}\text { Saya merasa mudah untuk mempelajari pengoperasian } \\
\text { website Detik.com }\end{array}$ \\
\hline & & $\begin{array}{l}\text { Saya berinteraksi dengan website Detik.com yang jelas dan } \\
\text { mudah di pahami }\end{array}$ \\
\hline & & $\begin{array}{l}\text { Saya merasa mudah untuk bernavigasi/menelusuri website } \\
\text { Detik.com }\end{array}$ \\
\hline & & Saya merasa website Detik.com mudah untuk di gunakan \\
\hline & & Website Detik.com memiliki tampilan yang menarik \\
\hline & & $\begin{array}{l}\text { Desain website Detik.com sudah sesuai dengan desain } \\
\text { sistem informasi berbasis web }\end{array}$ \\
\hline & & Website Detik.com memiliki kompetensi yang baik \\
\hline & & $\begin{array}{l}\text { Website Detik.com dapat memberikan pengaruh/pengalaman } \\
\text { yang positif bagi saya }\end{array}$ \\
\hline \multirow{7}{*}{2} & \multirow{7}{*}{ Kualitas Informasi } & Website Detik.com memberikan informasi yang akurat \\
\hline & & Website Detik.com memberikan informasi yang terpercaya \\
\hline & & Informasi yang di sajikan website Detik.com up to date \\
\hline & & $\begin{array}{l}\text { Website Detik.com memberikan informasi yang relevan } \\
\text { dengan apa yang di butuhkan }\end{array}$ \\
\hline & & $\begin{array}{l}\text { Website Detik.com memberikan informasi dengan bahasa } \\
\text { yang mudah di pahami }\end{array}$ \\
\hline & & $\begin{array}{l}\text { Website Detik.com memberikan informasi yang lengkap dan } \\
\text { terperinci }\end{array}$ \\
\hline & & $\begin{array}{l}\text { Informasi yang di sajikan website Detik.com dalam format } \\
\text { yang sesuai }\end{array}$ \\
\hline \multirow{3}{*}{3} & & Website Detik.com memiliki reputasi yang baik \\
\hline & & Saya merasa aman saat berinteraksi \\
\hline & & Website Detik.com sangat mnejaga informasi pribadi saya \\
\hline
\end{tabular}




\begin{tabular}{|l|l|}
\multirow{5}{*}{$\begin{array}{c}\text { Kualitas Layanan } \\
\text { Interaksi }\end{array}$} & $\begin{array}{l}\text { Website Detik.com memberikan ruang untuk personalisasi } \\
\text { bagi pengguna }\end{array}$ \\
& Website Detik.com memberikan ruang untuk komunitas \\
\cline { 2 - 2 } & $\begin{array}{l}\text { Website Detik.com memberikan kemudahan untuk } \\
\text { berkomunikasi }\end{array}$ \\
\cline { 2 - 2 } & $\begin{array}{l}\text { Saya merasa yakin bahwa semua informasi dan layanan } \\
\text { dalam website Detik.com berjalan dengan baik dan optimal }\end{array}$ \\
\hline
\end{tabular}

(Sumber: data diolah)

\subsection{Importance-Performance Analysis (IPA)}

Martila \& james (1997) memperkenalkan metode Importance-Performance Analysis (IPA) yang bisa digunakan untuk menganalisis kinerja sebuah organiasasi dengan mengukur kinerja yang dirasa penting oleh pelanggan dan kinerja yang diterima oleh pelanggan atau kinerja yang diberikan oleh website [11]. Hasil dari metode ini menampilkan diagram scater dari Importance-Performance Analysis dengan memilki kriteria-kriteria yang terdapat pada 4 kuadran. 4 kuadran tersebut adalah kuadran I (Prioritas Utama), kuadran II (Pertahankan Prestasi), kuadran III ( Prioritas Rendah), dan kuadran IV (Berlebihan).

\section{Hasil dan Pembahasan \\ 4.1 Detik.com}

PT Agranet Multicitra Siberkom (Agrakom) adalah pembuat produk media situs berita Detik.com. PT Agrakom didirikan pada bulan Oktober 1995 akan tetapi disahkan pada tahun 1996 oleh Budiono Darsono, Abdul Rahman, Didi Nugrahadi, dan Yayan Sopyan yang bergerak dibidang pembuatan web (web services). Pada tanggal 9 Juli 1998 server Detik.com bisa untuk dikunjungi, akan tetapi mulai beroperasi dengan layanan yang lengkap pada tanggal 9 Juli 1998. Pada tanggal 9 Juli itu kemudian dijadikan sebagai hari kelahiran Detik.com. Detik.com awalnya hanya berfokus pada berita politik, ekonomi, dan teknologi informasi. Akan tetapi, saat kondisi perpolitikan dan perekonomian sudah stabil Detik.com mengambil keputusan untuk meliput berita hiburan dan olahraga.

\subsection{Hasil Persentase Keseluruhan Webqual 4.0 Terhadap Importance}

Hasil dari perhitungan persentase dari semua variabel webqual 4.0 pada importance bisa dilihat pada Tabel 2. Data yang ada pada frekuensi didapatkan dari hasil rekapitulasi seluruh jawaban dari 70 responden dari skala $1-5$.

Tabel 2. Hasil Persentase Keseluruhan Webqual 4.0 Terhadap Importance

\begin{tabular}{|c|c|c|c|c|}
\hline No & Jawaban & Skala Likert (SL) & F & $\%$ \\
\hline 1 & Sangat Tidak Penting (STP) & 1 & 5 & 0,32 \\
\hline 2 & Tidak Penting (TP) & 2 & 31 & 2,01 \\
\hline 3 & Cukup Penting (CP) & 3 & 412 & 26,75 \\
\hline 4 & Penting (P) & 4 & 686 & 44,55 \\
\hline 5 & Sangat Penting (SP) & 5 & 406 & 26,36 \\
\hline \multicolumn{2}{|c|}{ TOTAL } & $\mathbf{1 . 5 4 0}$ & $\mathbf{1 0 0 \%}$ \\
\hline
\end{tabular}

Hasil dari perhitungan analisis dengan menggunakan skala likert yaitu:

$\begin{aligned} \text { Skor Ideal } & =5 \times 1.540 \\ & =7.700\end{aligned}$

Jumlah Skor $=6.077$

(Jumlah skor merupakan hasil dari penjumlahan setiap skala likert dikalikan dengan

Frekuensinya)

Persentase $\quad=\frac{6.077}{7.700} \times 100 \%=78,92 \%$ 
Jadi berdasarkan hasil yang diperoleh di atas dari 70 responden terdapat sebanyak $78,92 \%$ responden yang menyatakan penting. Artinya dalam variabel webqual 4.0 terhadap Importance didapatkan bahwasannya setiap variabel yang tersedia dalam webqual 4.0 memililki nilai harapan persentase sebesar $78,92 \%$. Besar persentase tersebut di skala likert termasuk kedalam kategori penting.

Tabel 3. Gambaran Persentase Skala Likert

\begin{tabular}{|c|c|c|c|c|}
\hline \multicolumn{1}{|c|}{$0 \%$} & $20 \%$ & $40 \%$ & $60 \%$ & $80 \%-100 \%$ \\
\hline STP & TP & CP & P & SP \\
\hline
\end{tabular}

\subsection{Nilai Persentase Keseluruhan Webqual 4.0 Terhadap Performance}

Hasil dari perhitungan persentase dari semua variabel webqual 4.0 terhadap importance bisa dilihat pada Tabel 4. Data yang terdapat dalam frekuensi didapatkan dari penjumlahan rekapitulasi seluruh jawaban dari 70 responden dari skala $1-5$.

Tabel 4. Hasil Persentase Keseluruhan Webqual 4.0 Terhadap Performance

\begin{tabular}{|c|c|c|c|c|}
\hline No & Jawaban & Skala Likert (SL) & F & $\%$ \\
\hline 1 & Sangat Tidak Setuju (STS) & 1 & 1 & 1,06 \\
\hline 2 & Tidak Setuju (TS) & 2 & 26 & 1,69 \\
\hline 3 & Cukup Setuju (CS) & 3 & 442 & 28,70 \\
\hline 4 & Setuju (S) & 4 & 748 & 48,57 \\
\hline 5 & Sangat Setuju (SS) & 5 & 323 & 20,97 \\
\hline \multicolumn{2}{|c|}{ TOTAL } & 1.540 & $\mathbf{1 0 0 \%}$ \\
\hline
\end{tabular}

Hasil dari perhitungan analisis dengan menggunakan skala likert yaitu:

Skor Ideal $=5 \times 1.540$

$$
=7.700
$$

Jumlah Skor $=5.986$

(Jumlah skor merupakan hasil dari penjumlahan setiap skala likert dikalikan dengan Frekuensinya)

Persentase $\quad=\frac{5.986}{7.700} \times 100 \%=77,74 \%$

Jadi berdasarkan hasil yang diperoleh di atas dari 70 responden terdapat sebanyak $77,74 \%$ responden yang menyatakan baik. Artinya dalam variabel webqual 4.0 terhadap Performance didapatkan bahwasannya setiap variabel yang terdapat dalam webqual 4.0 memililki nilai kinerja persentase sebesar $77,74 \%$. Besar persentase tersebut di skala likert termasuk kedalam kategori baik.

Tabel 5. Gambaran Persentase Skala Likert

\begin{tabular}{|c|c|c|c|c|}
\hline $0 \%$ & $20 \%$ & $40 \%$ & $60 \%$ & $80 \%-100 \%$ \\
\hline STB & TB & CB & B & SB \\
\hline
\end{tabular}

\subsection{Nilai Kualitas Berdasarkan Variabel}

Hasil dari perhitungan GAP dari semua variabel webqual bisa dilihat di tabel 6. Data yang ada pada semua variabel webqual 4.0 terhadap importance dan Performance adalah ratarata dari setiap nilai variabel itu sendiri yang bisa dilihat pada tabel 7 . 
Tabel 6. Perhitungan GAP Variabel Webqual

\begin{tabular}{|c|l|c|c|c|}
\hline No & Variabel Webqual 4.0 & Importance & Performance & GAP \\
\hline $\mathbf{1}$ & Usabillity Quality & 2,72 & 2,75 & 0,03 \\
\hline $\mathbf{2}$ & Information Quality & 2,82 & 2,73 & $-0,09$ \\
\hline $\mathbf{3}$ & Service Interaction Quality & 2,75 & 2,68 & $-0,07$ \\
\hline
\end{tabular}

Pada tabel 6 didapatkan hasil dari semua variabel webqual 4.0 pada variabel Usabillity Quality didapatkan hasil GAP sebesar 0,03, Information Quality diperoleh hasil GAP sebesar 0,09, dan Service Interaction Quality diperoleh hasil sebesar GAP -0,07.

\subsection{Nilai Pengukuran Kesenjangan GAP}

Sebelum mencari nilai kesenjangan website Detik.com, hal yang harus dicari terlebih dahulu adalah hasil rata-rata dari semua nilai importance dan performance. Rumus bisa dilihat pada persamaan (1).

Rata - Rata Importance $/$ Performance $=\frac{\text { Nilai rata-rata data jawaban responden per variabel }}{\text { Jumlah variabel }}$

Perhitungan nilai rata-rata dari Importance yaitu:

$$
\text { Rata - Rata Importance }=\frac{2,72+2,82+2,75}{3}=\frac{8,29}{3}=2,76
$$

Perhitungan nilai rata-rata dari Performance yaitu:

$$
\text { Rata - Rata Performance }=\frac{2,75+2,73+2,68}{3}=\frac{8,16}{3}=2,72
$$

Rumus untuk mendapatkan rata-rata nilai kesenjangan (GAP) pada website Detik.com bisa dilihat pada persamaan (2):

$$
Q i(G A P)=\text { Performance }(i)-\text { Importance }(i)
$$

Hasil dari pengukuran didapatkan skor nilai rata-rata sebesar 2,76 untuk importance dan skor nilai rata-rata sebesar 2,72 untuk performance.

$$
Q i(G A P) \quad=2,72-2,76=-0,04
$$

Hasil perhitungan tersebut dapat diambil kesimpulan bahwa nilai kesenjangan (GAP) terhadap website Detik.com memberikan nilai negatif yaitu sebesar $-0,04$. Angka tersebut merupakan gambaran dari kinerja website Detik.com pada saat ini dianggap kurang dan belum mampu menyanggupi harapan pengguna website Detik.com.

\subsection{Analisa Kuadran Dalam Importance dan Performance}

Penelitian ini mengunakan metode IPA yaitu pada analisis kuadran yang berguna untuk mengukur kinerja kepuasan yang diangap penting oleh pengguna dan kinerja kepuasan yang diterima oleh pengguna [4]. Hasil data yang didapatkan dari nilai rata- rata importance dan performance bisa dilihat pada Tabel 7 .

Tabel 7. Analisis Kuadran Dalam Importance dan Performance

\begin{tabular}{|l|c|c|c|}
\hline No & Variabel & Xi (Performance) & Yi (Importance) \\
\hline 1 & \multirow{2}{*}{ Usability Quality } & 2,75 & 2,68 \\
\cline { 3 - 4 } 2 & & 2,72 & 2,39 \\
\hline
\end{tabular}




\begin{tabular}{|c|c|c|c|}
\hline No & Variabel & Xi (Performance) & Yi (Importance) \\
\hline 3 & \multirow{6}{*}{ Usability Quality } & 2,78 & 2,79 \\
\hline 4 & & 2,81 & 2,75 \\
\hline 5 & & 2,65 & 2,73 \\
\hline 6 & & 2,76 & 2,77 \\
\hline 7 & & 2,82 & 2,87 \\
\hline 8 & & 2,73 & 2,81 \\
\hline 9 & \multirow{7}{*}{ Information Quality } & 2,67 & 2,72 \\
\hline 10 & & 2,77 & 2,83 \\
\hline 11 & & 2,87 & 2,92 \\
\hline 12 & & 2,65 & 2,76 \\
\hline 13 & & 2,83 & 2,94 \\
\hline 14 & & 2,64 & 2,85 \\
\hline 15 & & 2,67 & 2,72 \\
\hline 16 & \multirow{7}{*}{ Service Interaction Quality } & 2,81 & 2,84 \\
\hline 17 & & 2,72 & 2,80 \\
\hline 18 & & 2,74 & 2,79 \\
\hline 19 & & 2,63 & 2,69 \\
\hline 20 & & 2,47 & 2,53 \\
\hline 21 & & 2,61 & 2,72 \\
\hline 22 & & 2,76 & 2,87 \\
\hline & Total & 59,86 & 60,77 \\
\hline & Mean & 2,72 & 2,76 \\
\hline
\end{tabular}

Hasil dari gambar kuadran Importance-Performance Analysis (IPA) bisa dilihat pada gambar 1.

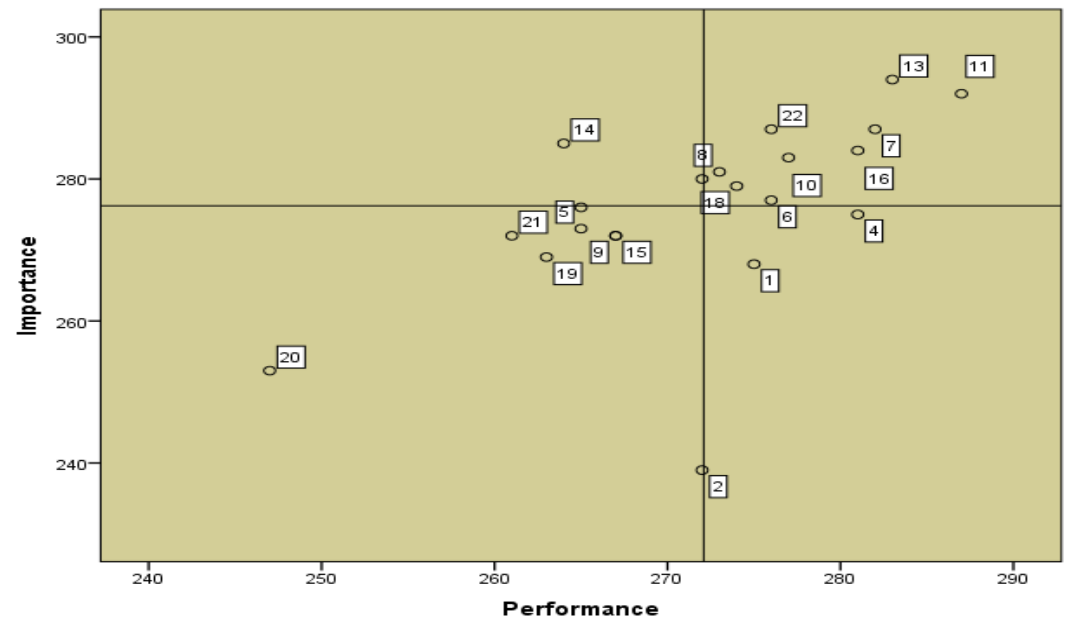

Gambar 1. Hasil Analisa 4 Kuadran IPA

1. Kuadran I (Prioritas Utama)

Indikator yang dirasa penting namun kinerja yang diberikan rendah merupakan indikator yang termasuk pada kuadran I, maka harus ditingkatkan yaitu indikator nomor 14 "Informasi lengkap dan terperinci".

2. Kuadran II (Pertahankan Prestasi)

Indikator yang dirasa penting dan kinerja yang diberikan baik atau sudah memenuhi harapan pengguna merupakan indikator yang termasuk dalam kuadran II yaitu indikator tiga "Mudah bernavigasi/menelusuri website", Indikator yang kedua ialah indikator nomor tujuh yaitu "Website Detik.com memiliki kompetensi yang baik", Indikator yang ketiga ialah indikator nomor 
delapan yaitu "Website Detik.com memberikan pengalaman yang baik/positif", Indikator yang keempat ialah indikator nomor sepuluh yaitu "Website Detik.com memberikan informasi yang dapat dipercaya", Indikator yang kelima ialah indikator nomor sebelas yaitu "Website Detik.com memberikan informasi yang up to date", Indikator yang keenam ialah indikator nomor tiga belas yaitu "Informasi yang disampaikan oleh website Detik.com disajikan dalam bahasa yang mudah dipahami", Indikator yang ketujuh ialah indikator nomor enam belas yaitu "Website Detik.com memiliki reputasi yang baik", Indikator yang kedelapan ialah indikator nomor tujuh belas yaitu "Merasa aman saat berintaksi dengan website Detik.com", Indikator yang kesembilan ialah indikator nomor delapan belas yaitu "Website Detik.com menjaga informasi pribadi", Indikator yang kesepuluh ialah indikator nomor dua puluh dua yaitu "Website Detik.com berjalan dengan baik dan optimal".

\section{Kuadran III (Prioritas Rendah)}

Indikator yang dirasa kurang penting dan kinerja yang diberikan juga tidak baik merupakan indikator yang termasuk dalam kuadran III . Indikator yang pertama ialah nomor lima yaitu "Website Detik.com memberikan tampilan yang mernarik", Indikator kedua nomor sembilan yaitu "Website Detik.com memberikan informasi yang akurat", Indikator ketiga nomor dua belas yaitu "Website Detik.com memberikan informasi yang relevan", Indikator keempat nomor lima belas yaitu "Website Detik.com memberikan informasi yang sesuai dengan format", Indikator kelima nomor sembilan belas yaitu "Website Detik.com memberikan ruang untuk personalisasi", Indikator keenam nomor dua puluh yaitu "Website Detik.com memberikan ruang untuk komunitas", Indikator ketujuh nomor dua puluh satu yaitu "Website Detik.com memberikan kemudahan untuk berkomunikasi dengan pihak website Detik.com".

\section{Kuadran IV (Berlebihan)}

Indikator yang dianggap tidak penting oleh pengguna namun kinerja yang diberikan baik atau berlebihan merupakan indikator yang termasuk pada kuadran IV. Indikator yang pertama nomor satu yaitu "Mudah untuk mengoperasikan website Detik.com", Indikator kedua nomor dua yaitu "website Detik.com jelas dan mudah dipahami", Indikator ketiga nomor enam yaitu "Desain website Detik.com sudah sesuai".

\subsection{Kualitas Layanan Website Detik.com Dilihat Dari Importance Dan Performance}

Website Detik.com berlandaskan pada variabel webqual 4.0 yang dibutuhkan oleh pengguna, 70 responden $78,92 \%$ menyatakan penting pada importance dan dalam webqual 4.0 terhadap performance sebesar $77,74 \%$ menyatakan baik. Berdasarkan hasil tersebut dapat diimplikasikan bahwa responden menganggap kinerja yang ditawarkan oleh Detik.com sudah masuk kategori baik, akan tetapi kinerja yang diberikan masih dibawah nilai harapan yang diberikan oleh responden yaitu dengan selisih nilai $1,18 \%$.

Metode IPA memberikan hasil bawa didapatkan indikator yang harus ditingkatkan kualitas layanannya, karena responden merasa kualitas yang ditawarkan atau diberikan belum baik sedangkan harapan responden atau pengguna tinggi pada indikator tersebut. Indikator nomor 14 "Website Detik.com memberikan informasi yang lengkap dan terperinci" merupakan indikator yang terdapat pada kuadran I ialah prioritas utama yang harus ditingkatkan kualitasnya. Hal ini mengimplikasikan bahwa pihak Detik.com khususnya bagian pengelola website Detik.com harus lebih memprioritaskan untuk diperhatikan kualitasnya yaitu indikator yang berhubungan dengan informasi yang akan tampilkan di website, khususnya pada informasi yang detail atau lengkap dan terperinci.

\subsection{Hasil Kualitas Layanan Website Detik.com Berdasarka Nilai GAP}

Berlandaskan pada hasil dari analisis GAP memberikan hasil bahwa keseluruhan variabel memperoleh hasil negatif kecuali variabel Usability Quality, dari hasil tersebut bisa disimpulkan bahwa kualitas yang ada pada website Detik.com sekarang masih belum sesuai dengan harapan pengguna website Detik.com. Variabel yang menunjukkan hasil nilai negatif yaitu variabel Information Quality dan Service Interaction Quality. Hal ini mengandung implikasi agar kedepannya pihak Detik.com khususnya bagian pengelola website Detik.com lebih memperhatikan kualitas website pada indikator-indiktor yang ada terdapat dalam variabel Information Quality dan Service Interaction Quality, sehingga mampu menyanggupi harapan 
dari para penggunanya khususnya indikator-indikator yang dianggap penting dan yang membutuhkan prioritas lebih untuk dilakukan perbaikan kualitasnya.

$-0,04$ merupakan hasil dari nilai rata-rata kesenjangan (GAP) pada website Detik.com. Hasil tersebut menandakan bahwa tingkat kinerja yang ditawarkan atau diberikan oleh website Detik.com masih kurang dan belum bisa mampu menyanggupi harapan penggunanya, sehingga perlu dilakukannya perbaikan atau peningkatan pada setiap indikator-indikator webqual 4.0 yang berdasarkan pada hasil perolehan dari analisis Importance-Performance Analysis (IPA).

\section{Kesimpulan}

Metode Website quality (Webqual) 4.0 dan metode Importance Performance Analysis (IPA) adalah metode yang dipakai pada penelitian ini digunakan untuk mengetahui kualitas dari layanan yang diberikan oleh website Detik.com dan untuk mencaritahu indikator-indikator yang perlu ditingkatkan kualitasnya. Hasil dari perhitungannya memberikan hasil negatif $(<0)$ yaitu sebesar -0,04. Angka tersebut mengartikan bahwa taraf kinerja yang ditawarkan atau diberikan oleh website Detik.com masih kurang dan belum bisa menyanggupi harapan penggunanya. Nilai perolehan setelah menganalisis dengan menggunakan kuadran IPA didapatkan 1 indikator yang terdapat pada kuadran I artinya indikator yang dijadikan prioritas utama untuk dilakukan perbaikan kualitasnya karena mempunyai kepentingan atau harapan yang tinggi sedangkan kinerja yang diberikan rendah, yaitu indikator nomor 14 "Informasi lengkap dan terperinci".

Sepuluh indikator pada kuadran II yang harus dipertahankan kualitasnya disebabkan tingkat kepentingan dan kinerjanya sama-sama tinggi yaitu indikator tiga "Mudah bernavigasi/menelusuri website", Indikator yang kedua ialah indikator nomor tujuh yaitu "Website Detik.com memiliki kompetensi yang baik", Indikator yang ketiga ialah indikator nomor delapan yaitu "Website Detik.com memberikan pengalaman yang baik/positif", Indikator yang keempat ialah indikator nomor sepuluh yaitu "Website Detik.com memberikan informasi yang dapat dipercaya", Indikator yang kelima ialah indikator nomor sebelas yaitu "Website Detik.com memberikan informasi yang up to date", Indikator yang keenam ialah indikator nomor tiga belas yaitu "Informasi yang disampaikan oleh website Detik.com disajikan dalam bahasa yang mudah dipahami", Indikator yang ketujuh ialah indikator nomor enam belas yaitu "Website Detik.com memiliki reputasi yang baik", Indikator yang kedelapan ialah indikator nomor tujuh belas yaitu "Merasa aman saat berintaksi dengan website Detik.com", Indikator yang kesembilan ialah indikator nomor delapan belas yaitu "Website Detik.com menjaga informasi pribadi", Indikator yang kesepuluh ialah indikator nomor dua puluh dua yaitu "Website Detik.com berjalan dengan baik dan optimal".

Tujuh indikator pada kuadran III pada kuadran ini mempunyai taraf kinerja dan kepentingannya sama-sama rendah, bisa dikatakan kinerja dari sistem tidak begitu mempengaruhi kepentingan yaitu indikator pertama adalah nomor lima yaitu "Website Detik.com memberikan tampilan yang menarik", indikator yang kedua adalah indikator nomor sembilan yaitu "Website Detik.com memberikan informasi yang akurat", indikator ketiga dua belas yaitu "Website Detik.com memberikan informasi yang relevan", Indikator keempat nomor lima belas yaitu "Website Detik.com memberikan informasi yang sesuai dengan format", Indikator kelima nomor sembilan belas yaitu "Website Detik.com memberikan ruang untuk personalisasi", Indikator keenam nomor dua puluh yaitu "Website Detik.com memberikan ruang untuk komunitas", Indikator ketujuh nomor dua puluh satu yaitu "Website Detik.com memberikan kemudahan untuk berkomunikasi dengan pihak website Detik.com".

Empat indikator pada kuadran IV kuadaran ini dinyatakan berlebihan karena kualitas layanan yang terdapat pada kuadran ini dianggap pengguna kurang penting, tetapi kinerja yang diberikan dinilai terlalu berlebihan, yaitu Indikator yang pertama nomor 1 yaitu "Mudah untuk mengoperasikan website Detik.com", Indikator kedua nomor 2 yaitu "website Detik.com jelas dan mudah dipahami”, Indikator ketiga nomor 6 yaitu "Desain website Detik.com sudah sesuai", kuadaran ini dikatakan berlebihan, kualitas layanan dalam kuadran ini dianggap pengguna kurang penting namun pelaksanaan kinerjanya dinilai terlalu berlebihan.

Saran yang diberikan oleh peneliti bagi pihak Detik.com khususnya pihak-pihak yang bertanggung jawab dalam pengelolaan website Detik.com dan pihak-pihak yang berkeinginan untuk melakukan penelitian sejenis, yaitu:

1. Hasil dari penelitian ini yaitu memperoleh hasil negative yaitu sebesar -0,04 maka pihak Detik.com perlu meningkatkan kinerja website agar tingkat kinerja (Performance) lebih tinggi dibandingkan tingkat harapan (Importance). Melakukan perbaikan yang 
berdasarkan pada hasil dari penelitian ini yaitu pada variabel Information Quality dan service interaction Quality khsusnya pada indikator yang termasuk kedalam kuadran I yaitu nomor 14 "Informasi lengkap dan terperinci", evaluasi dan perbaikan pada website Detik.com sebaiknya dilakukan secara berkelanjutan.

2. Evaluasi dilakukan secara berjekelanjutan terhadap layanan agar dapat memperbaiki kualitas website Detik.com serta mempertahankan dan meningkatkan layanan yang sudah baik kualitasnya yang dapat dilihat pada hasil dari kuadran II.

Saran untuk pihak yang ingin melakukan penelitian sejenis:

1. Populasi yang diambil diharapkan tidak hanya berasal dari kalangan mahasiswa tapi juga mengikutsertakan masyarakat lain yang juga menggunakan atau mengunjungi website Detik.com atau lainnya.

2. Penelitian selanjutnya diharapkan tidak hanya meneliti satu website, tetapi meneliti dua website sekaligus dengan catatan website yang sejenis lalu membandingkan hasilnya.

3. Penelitian selanjutnya juga diharapkan indikator yang digunakan dapat menambahkan atau bahkan mengembangkan metode yang lain yang bisa digunakan dalam mengukur kualitas sebuah website.

\section{Daftar Pustaka}

[1] P. A. Jaya Kusuma, I. K. A. Purnawan and N. M. I. Mandenni, "Aplikasi Sistem Informasi Hotel Berbasis Android," Merpati, vol. 3, pp.43-51, 2016.

[2] I. B. P. Gamaswara, A. A. K. Oka Sudana and N. M. I. Madenni, "Perancangan Sistem Infromasi Manajemen Modul Layanan Pada Rumah Sakit," Lontar Komputer, vol. 6, pp.163-174, 2015.

[3] S. A. Pratiwi, I. M. Sukarsa and I. K. A. Purnawan, "Rancang Bangu Aplikasi Sistem Pemesanan Bunga Berbasis Android," Merpati, vol. 2, pp. 205-214, 2014.

[4] Syarifuddin, Y. Jurnalistik Terapan. Bogor: Ghalia Indonesia. 2010.

[5] Anisatul, K. Kepuasan Mahasiswa UIN Jakarta Terhadap Situs Media Online: Komparasi Tribunnews.com Dengan Detik.com. Fakultas IImu Dakwah Dan IImu Komunikasi Universitas Islam Negeri Negeri Syarif Hidayatullah. 2017.

[6] Barnes, S. J., \& Vidgen, R. T. Measuring Web Quality Improvements a Case Study of The Forum on Strategic Management Knowledge Exchange. Journal of Industrial Management And Data Systems. 2003.

[7] Martila, J. A., \& James, J. C. Importance-Performance Analysis. Journal of Marketing. 1997. Vol. 41, 77-79.

[8] Sugiyono, E. Metode Penelitian Kuantitatif, Kualitatif, dan R\&D. Bandung: ALFABETA. 2015.

[9] Sugiyono, E. Metodologi Penelitian Bisnis. bandung: ALFABETA. 2014.

[10] Arikunto. Prosedur Penelitian: Suatu Pendekatan Praktek. Jakarta: Rineka Cifta.2010.

[11] Algifari. Mengukur Kualitas Layanan dengan Indeks Kepuasan Metode IPA.Yogyakarta: BPFE. 2016

[12] Monalisa, Siti dan Arrofik Zulkarnaen. Evaluasi Kualitas Layanan Sistem Informasi Kepegawaian Menggunakan Metode Servqual. Jurnal Sistem Informasi, 2014. vol.13, No.2, ISSN 1693-2390.

[13] Ali, M. N. Pengukuran Kualitas Website UIN Sunan Kalijaga Menggunakan Metode Webqual 4.0. Fakultas Sains dan Teknologi Universitas Islam Negeri Sunan Kalijaga. 2017.

[14] Anif, P. K. Amalisis Kualitas Layanan Website Tokpedia Terhadap Kepuasan Pengguna Menggunakan Metode Webqual 4.0. 2016. Vol.30.n0.pp.2930-2937.

[15] Brilian, P. Analisis Kualitas Website Pemerintah Daerah Kabupaten Semarang menggunakan Metode Webwual 4.0 dan IPA. Fakultas Teknologi Informasi Universitas Kristen Satya Wacana. 2017.

[16] Budi Setiawan, M. F. Analisis Kualitas Layanan Website Menggunakan Metode Webqual Webqual dan Importance-Performance Analysis (IPA) Pada Situs Kaskus. 2015. Vol.2.no.3.pp154-157.

[17] Chairunnisa, faraz. Analisis Kualitas Website Noss-A Assurance PT. Telkom Kebayoran Baru, Jakarta Selatan. Skripsi. Jurusan Administrasi Bisnis Universitas Telkom. 2017. 
[18] Juliansyah, N. Metodologi Penelitian:Skripsi, Tesis, Disertasi, dan karya ilmiah. Jakarta: Kencana Prenadamedia Group. 2014.

[19] Laodon Kenneth C. dan Laudon Jane Price. Sistem Informai Manajemen: Mengelola Perusahaan Digital Edisi 8 Terjemahan: Erwin Philippus, Yogyakarta: ANDI, 2005.

[20] Munawir, L. A. Sistem Informasi Manajemen. Banda Aceh: Lembaga Komunitas Informasi Teknologi Aceh (KITA). 2018.

[21] Nugroho, A. A. Analisis Pengaruh Kualitas Website UMS Terhadap Kepuasan Pengguna dengan Metode Webqual 4.0. Fakultas Teknik Universitas Muhamammdiyah Surakarta. 2018.

[22] Rahmaini, S. N. Analisis Kualitas Website Akademik Menggunakan Metode Webqual 4.0 dan Importance-Performance Analisys (IPA). Universitas Islam Negeri Syarif Hidayatullah Jakarta. 2018.

[23] Riadi, A. Memahami Metode-Metode Penelitian. Jogjakarta: Ar-Ruzz Media. 2016.

[24] Safira, N. R. Analisis Kualitas Website Akademik Menggunakan Metode Webqual 4.0 Dan Importance-Performance Analysis (IPA). 2018.

[25] Wella, H. U. Analisis Kualitas Website E-Feeling Menggunakan Metode Webqual dan IPA. Universitas Islam Negeri Raden Fatah Palembang. 2018. 